
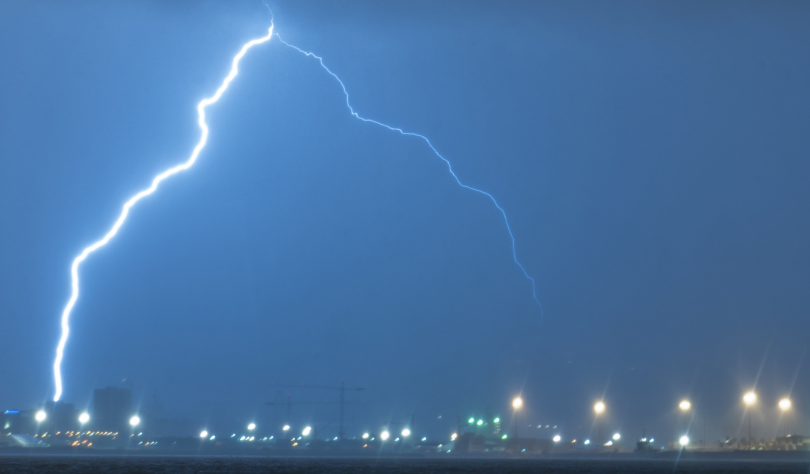

\title{
Lluvias torrenciales en Málaga (Feb 2017)
}

LUIS HONTORIA HERNÁNDEZ

Centro Nacional de Predicción (CNP), Agencia Estatal de Meteorología (AEMET)

DAVID MANCEBo ATIENZA

http: // objetivotormenta. blogspot. com.es/

@objtormentas

Uno debe conocer la llamada "lección de un aguacero". Un hombre, atrapado en una lluvia repentina en el camino, corre para no mojarse ni empaparse. Una vez que uno da por sentado que en la lluvia, naturalmente, se moja, puede estar en un estado de ánimo tranquilo, incluso cuando su piel esté empapada. Esta lección se aplica a todo.

YAMAMOTO TSUNETOMO

El domingo 19 de febrero de 2017 Málaga sufrió un episodio de lluvias torrenciales. En el área de la capital cayó una fuerte tromba de agua, registrando más de $150 \mathrm{~mm}$ acumulados, la mayoría caídos de madrugada. El episodio tenía una difícil predecibilidad, con mucha variabilidad espacial, propia de los casos en los que la convección juega un papel primordial. En Almería, uno de los puntos donde podían esperarse también precipitaciones intensas, no llovió nada. Realizamos en este capítulo un ensayo de predicción de precipitación acumulada en 24 horas para ese domingo día 19 de febrero de 2017 en esa zona, usando la pasada de las 00 UTC del día 16 de febrero de los sistemas de predicción del European Centre for Medium-range Weather Forecasts (ECMWF), tanto el modelo ECHRES como del ECENS.

Palabras clave: sistemas de predicción por conjuntos aplicados a la predicción de corto y medio plazo, predicción probabilista, lluvias torrenciales en Málaga febrero 2017. 


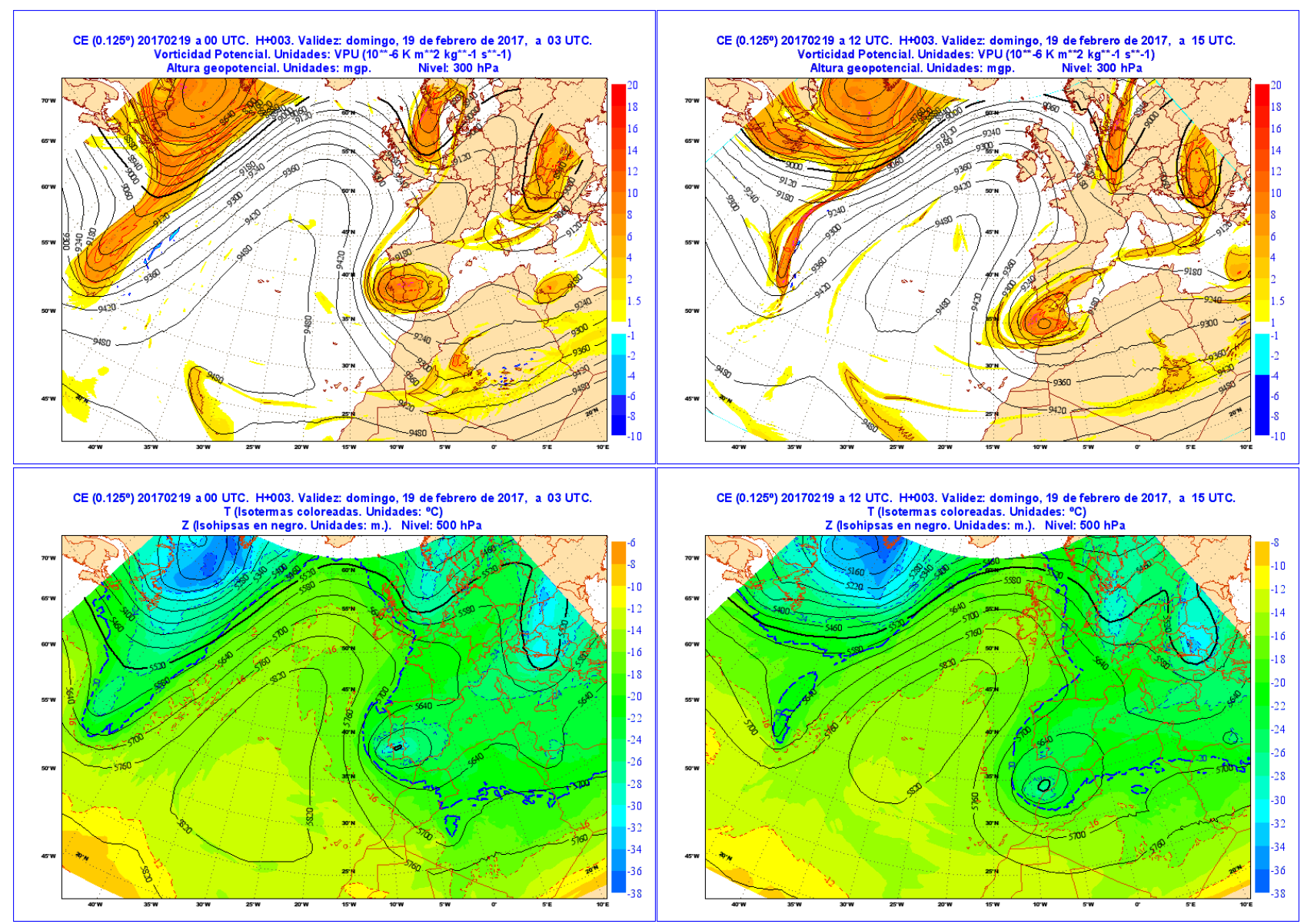

Figura 55.1: Situación sinóptica desarrollada el 19-02-2017, a las 03 UTC (izquierda) y a las 15 UTC (derecha). Campos previstos a 3 horas por el modelo ECHRES (sec. 19.2 en la página 291), prácticamente un análisis, de ahí que las horas no sean 00 y 12 UTC sino 03 y 15 UTC. Arriba, vorticidad potencial y altura geopotencial en 300 hPa y abajo temperatura y altura geopotencial en 500 hPa. En conjunción con la Figura 55.2 en la página siguiente puede identificarse una depresión aislada de niveles altos (DANA), con valores muy altos de vorticidad potencial ( $8 \mathrm{VPU}$ ) y embolsamiento frío en el núcleo, claramente aislada en niveles medios y altos.

\subsection{Descripción meteorológica e impactos}

\section{DAVID MANCEBo ATIENZA \\ http://objetivotormenta.blogspot.com.es/ \\ @ objtormentas}

\subsubsection{Situación sinóptica}

En este capítulo, para hacer la predicción del 19 de febrero de 2017, usaremos la pasada de las 00 UTC del día 16 de febrero de los sistemas de predicción del European Centre for Medium-range Weather Forecasts (ECMWF, sec. 19.2 en la página 291), tanto el modelo determinista ECHRES (sec. 19.2 en la página 291) como el sistema(s) de predicción por conjuntos (SPC) ECENS (sec. 19.3 en la página 293) [2]. Durante las últimas horas del 18 de febrero de 2017 y primeras del día siguiente, una DANA fue descendiendo de noroeste a suroeste de la península ibérica provocando un aumento gradual de la inestabilidad a su paso (Figura 55.1).

En la provincia de Málaga el viento giraría a levante de cara a la madrugada del 19 de febrero, adquiriendo intensidad con el paso de las horas con una clara zona de convergencia que los modelos situaban próxima a la capital. El levante es un viento húmedo que, en determinadas ocasiones, como es el caso estudiado en el presente capitulo, provoca un aumento acusado de la inestabilidad en puntos del valle del Guadalhorce o en el entorno de la capital.

Bajo un fuerte contraste térmico, convergencias locales y un panorama que los modelos mesoescalares presentaban una y otra vez como peligroso, se desarrolló este episodio en el que era hasta cierto punto previsible la formación de células de tormenta muy estáticas en torno a la capital de la Costa del Sol. 


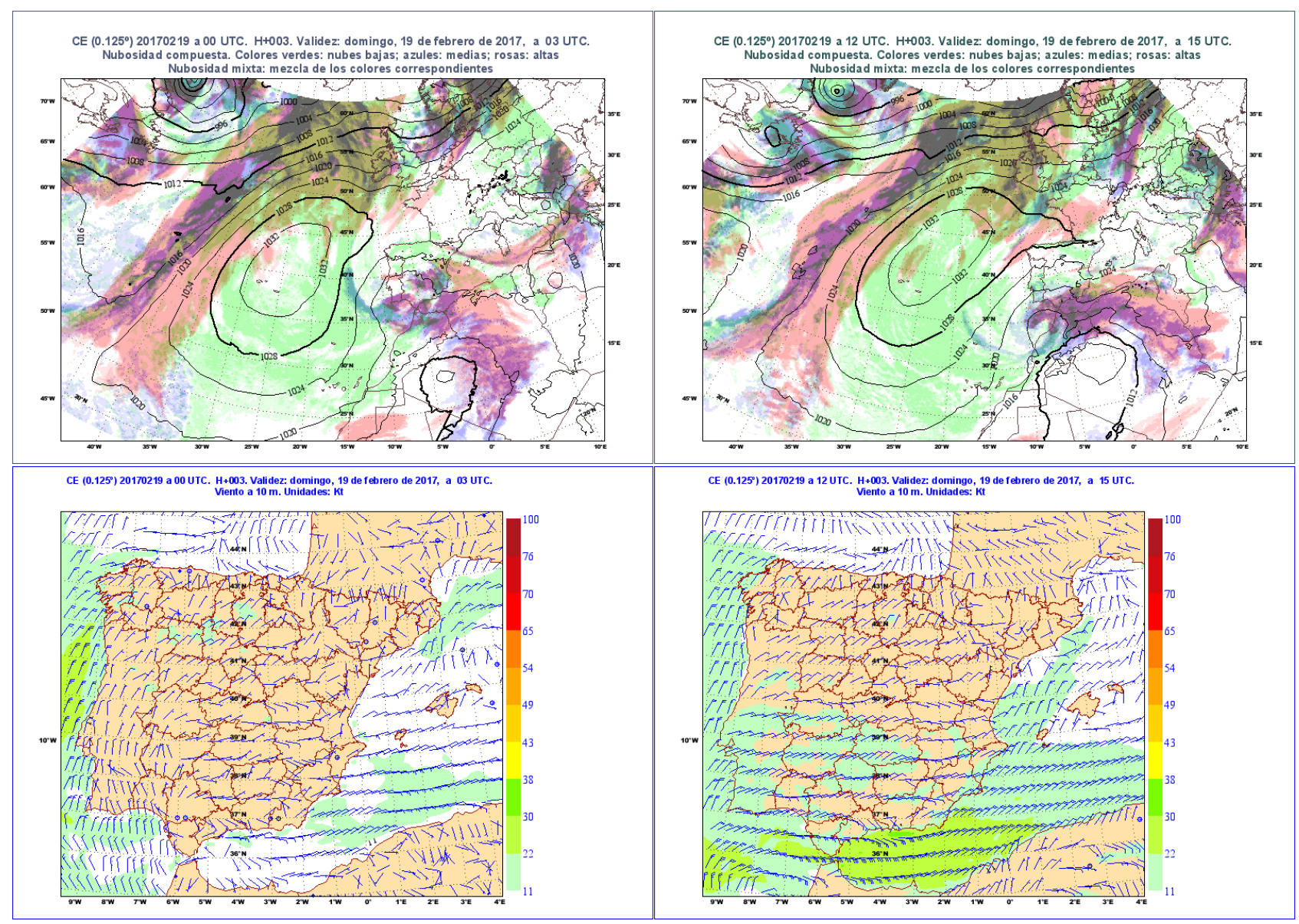

Figura 55.2: Como en la Figura 55.1 en la página anterior, desplegamos ahora arriba presión reducida al nivel del mar con cobertura nubosa en superficie y, abajo, viento medio representado con barbas, resaltando con colores la velocidad. Puede distinguirse cómo en las costas de Málaga se pasa en 12 horas de un viento flojo del este a un viento medio de Levante de 25 nudos.

\subsubsection{Principales impactos}

La tormenta comenzó en la zona occidental de la capital, alcanzando su mayor virulencia en las zonas centro y este de la misma, tornándose estática y agravando los impactos. Es probable que muchas infraestructuras no tuvieran resistencia adecuada para eventos de este tipo, infrecuentes pero no tan raros.

Aunque esta tormenta se produjo de madrugada, ese día era sábado, con muchas personas acudiendo a los locales de ocio del centro (discotecas, pubs... ), en algunos de los cuales brotaron grandes goteras por la intensidad de la precipitación.

Los principales problemas se produjeron en la zona del Cerrado Calderón donde hubo corrimientos de tierra que afectaron a muros de contención, con desprendimientos y hundimientos de la calzada. Hasta 200 incidencias tuvo que atender el 112, destacando el rescate de dos mujeres, una de ellas embarazada, por parte del Real Cuerpo de Bomberos en la subida a la citada zona. Así mismo, dos jóvenes cayeron 25 metros en un tremendo socavón (Figuras 55.3 y 55.4 en la página siguiente) por la misma zona pero sin lamentar afortunadamente mayores problemas. Este socavón se «tragó» hasta tres vehículos.

En la misma área muchos cascotes fueron arrastrados por la fuerza del agua por numerosas calles y varios vehículos fueron desplazados y se empotraron contra el mobiliario urbano. Las alcantarillas saltaron, con gran peligro para la circulación. 

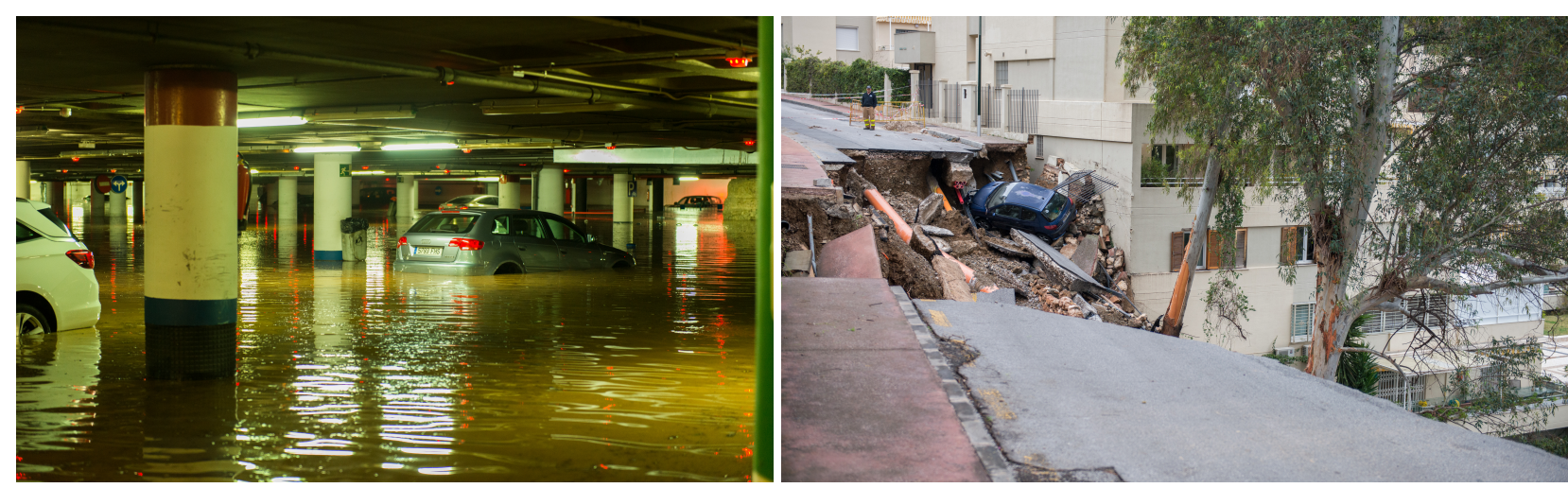

Figura 55.3: Garaje de la Plaza de la Marina inundado (izquierda) y carretera socavada en Cerrado Calderón (derecha), área metropolitana de Málaga, el 17 de febrero de 2017, fotografías de DAVID MANCEBO.

Los arroyos de la zona sufrieron una espectacular crecida, como el Arroyo de la Caleta, que se desbordó poco antes de la desembocadura y provocó la inundación de varias calles y garajes de la zona, convirtiéndola en un lodazal, sobre todo el Pasaje de Sancha. Por desgracia, estos arroyos suelen estar muy olvidados en cuanto a limpieza y mantenimiento e incluso algunos vecinos aparcan, inconscientes del peligro, en sus cauces, mayoritariamente secos, lo que puede provocar más desgracias en situaciones como ésta.

La fuerte granizada que acompañaba a la tormenta tiñó de blanco la zona centro y este de la capital, afectando por ejemplo a la estructura del techo de los Baños del Carmen.
La zona centro fue una zona particularmente afectada, con inundaciones en muchas calles y garajes, destacando el garaje de la Plaza de la Marina donde quedaron atrapados más de 30 vehículos, en algunos de los cuales el agua alcanzó una altura muy considerable. Por otro lado, el sanatorio de Gálvez vio afectada su sala de radiología.

Algunos conductores se vieron atrapados en sus vehículos en varias calles, como la zona de Ollerías y la antigua N340 en la zona de El Palo.

La tromba de agua dejó al menos una veintena de desalojados [1], en varias calles de la citada zona de Cerro Calderón, así como en Pedregalejo y La Mosca.
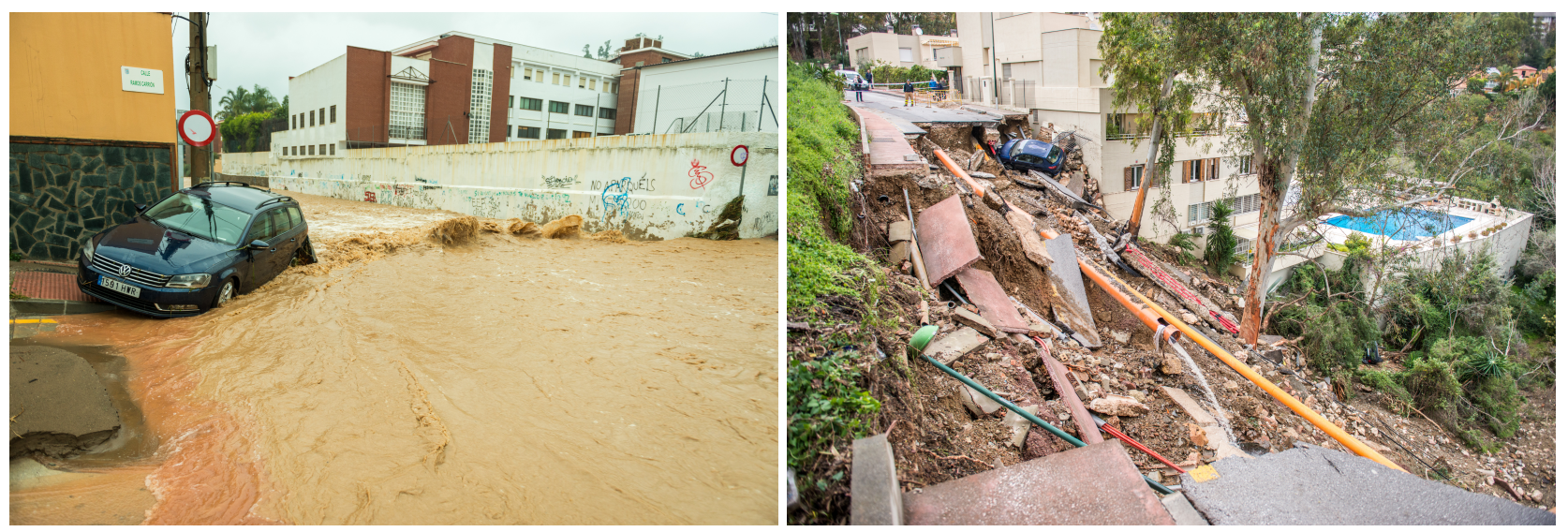

Figura 55.4: Inundaciones en las inmediaciones de la calle Ramos Carrión (izquierda) y perspectiva del socavón mostrado anteriormente (derecha), por donde cayeron hasta tres coches, fotografias de DAVID MANCEBO. 


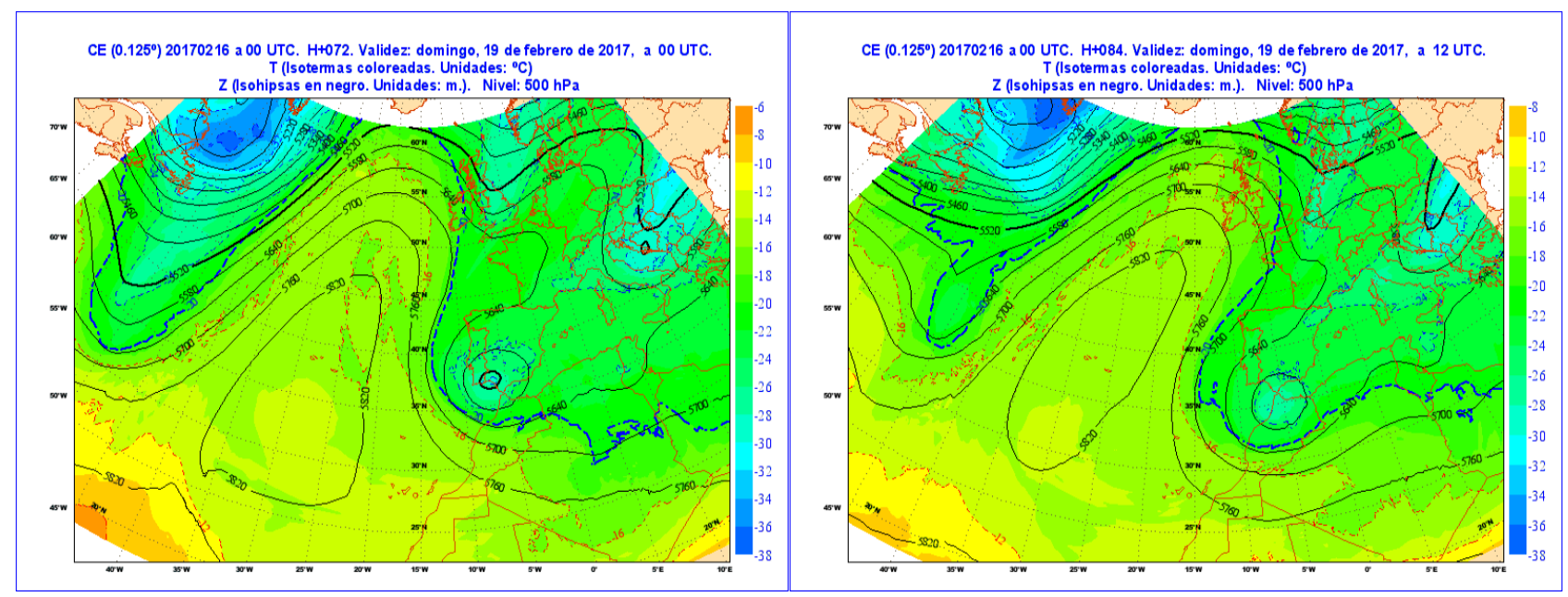

Figura 55.5: En los mapas previstos para el domingo 19 de febrero de 2017 puede apreciarse una DANA centrada sobre el área del Estrecho (ver texto). Agencia Estatal de Meteorología (AEMET) 2017.

\subsection{Predicción de medio plazo}

\section{LUIS HONTORIA HERNÁNDEZ CNP, AEMET}

Con una perspectiva de 3 días vista, se estudia la situación tanto con el modelo determinista ECHRES (sec. 19.2 en la página 291) como con el sistema de predicción por conjuntos ECENS (sec. 19.3 en la página 293).

\subsubsection{Modelo determinista ECHRES}

La Figura 55.5 muestra la situación prevista en niveles medios de la troposfera $(500 \mathrm{hPa})$ para el domingo
19 de febrero de 2017 por la pasada de las 00 del día 16 del ECHRES, a las 00 (izquierda) y a las 12 UTC (derecha). Se muestra temperatura (colores) y altura geopotencial (isohipsas). Tal como se describe en la sección 55.1 .1 en la página 828 , la situación viene condicionada por la presencia de una DANA centrada sobre el área del Estrecho con un ńucleo de $-28^{\circ} \mathrm{C}$ sobre el sur de Portugal.

La Figura 55.6 muestra la situación prevista en superficie para el domingo 19 de febrero de 2017 por la pasada de las 00 del día 16 del ECHRES. A la izquierda presión reducida al nivel del mar (isobaras) con nubosidad compuesta (colores) a las 00 UTC. A la derecha, precipitación acumulada prevista de 00 a 24 UTC.

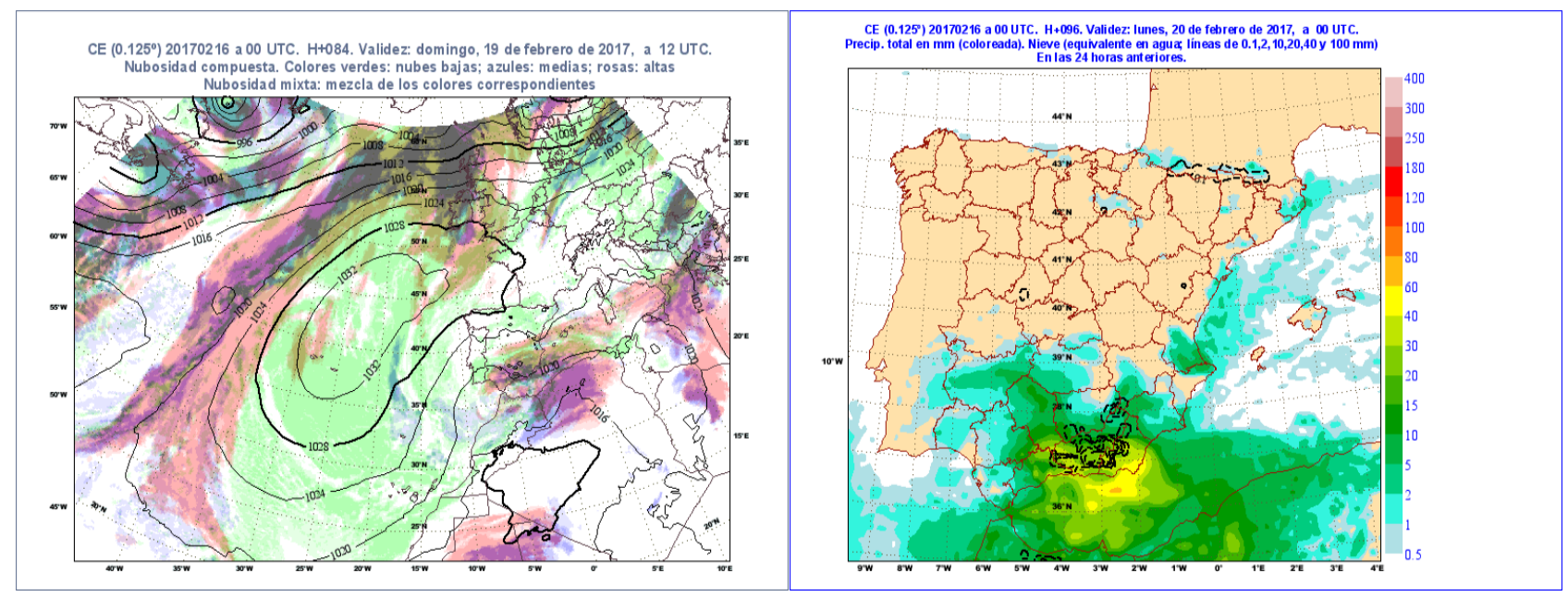

Figura 55.6: A la izquierda, anticiclón atlántico al noroeste de la península ibérica y una baja amplia y poco profunda sobre el norte de África, lo que genera un flujo de vientos de levante poco intensos sobre la Península. A la derecha, precipitación acumulada prevista para este día (ver texto). AEMET 2017. 
Se puede apreciar cómo domina el anticiclón atlántico al noroeste de la península ibérica y una baja amplia y poco profunda sobre el norte de África, lo que genera un flujo de vientos de levante poco intensos sobre la Península.

La presencia de la DANA descrita más arriba propicia un campo de precipitación acumulada en las 24 horas del domingo previsto por el modelo en la figura de la derecha. Con este entorno sinóptico son previsibles precipitaciones persistentes en Andalucía oriental, acumulándose en comarcas del área litoral cantidades que pueden superar los $40 \mathrm{~mm}$ y en comarcas del prelitoral y en Melilla los $20 \mathrm{~mm}$. Las precipitaciones, con menor persistencia, afectarán al resto de Andalucía, Ceuta, sur de Extremadura y de
Castilla-La Mancha, Murcia y Valencia. Se observan señales de precipitación débil en zonas aisladas del norte peninsular, resto del litoral mediterráneo oriental y Baleares.

\subsubsection{ECENS: consistencia con ECHRES}

En cuanto a la pasada del ECENS de las 00 UTC del día 16, puede observarse que el núcleo de la DANA es ligeramente más frío en el miembro de control que en el determinista ECHRES (ver sección 27.3.1 en la página 405). No obstante, la similitud entre ECHRES y el control presupone un razonable grado de predecibilidad al menos a nivel sinóptico. Figura 55.7.

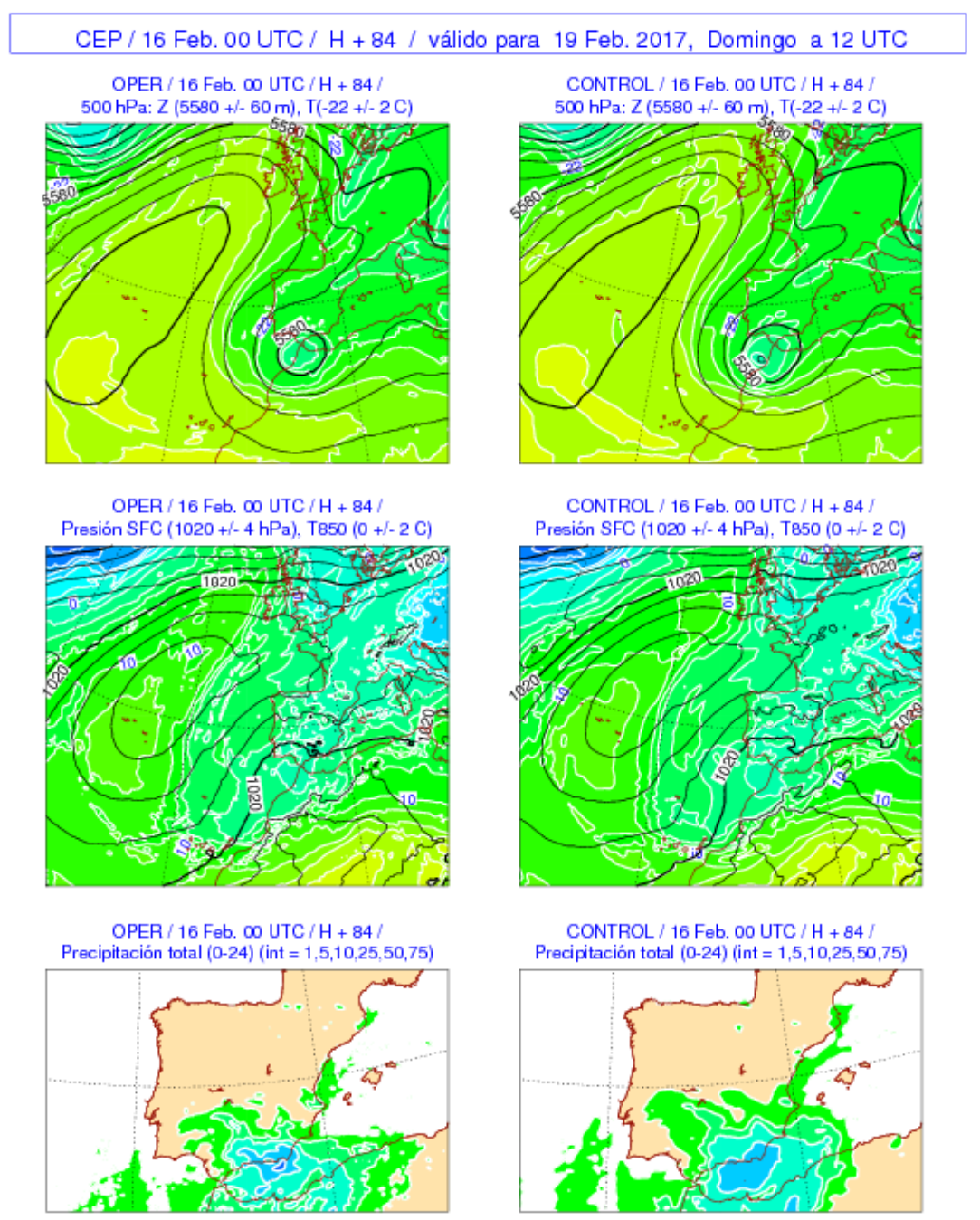

Figura 55.7: Comparación de ECHRES (columna izquierda) con el miembro de control del ECENS (columna derecha). Las filas muestran niveles medios-altos, niveles bajos-superficie y precipitación acumulada en $24 \mathrm{~h}$ (ECMWF). AEMET 2017. 


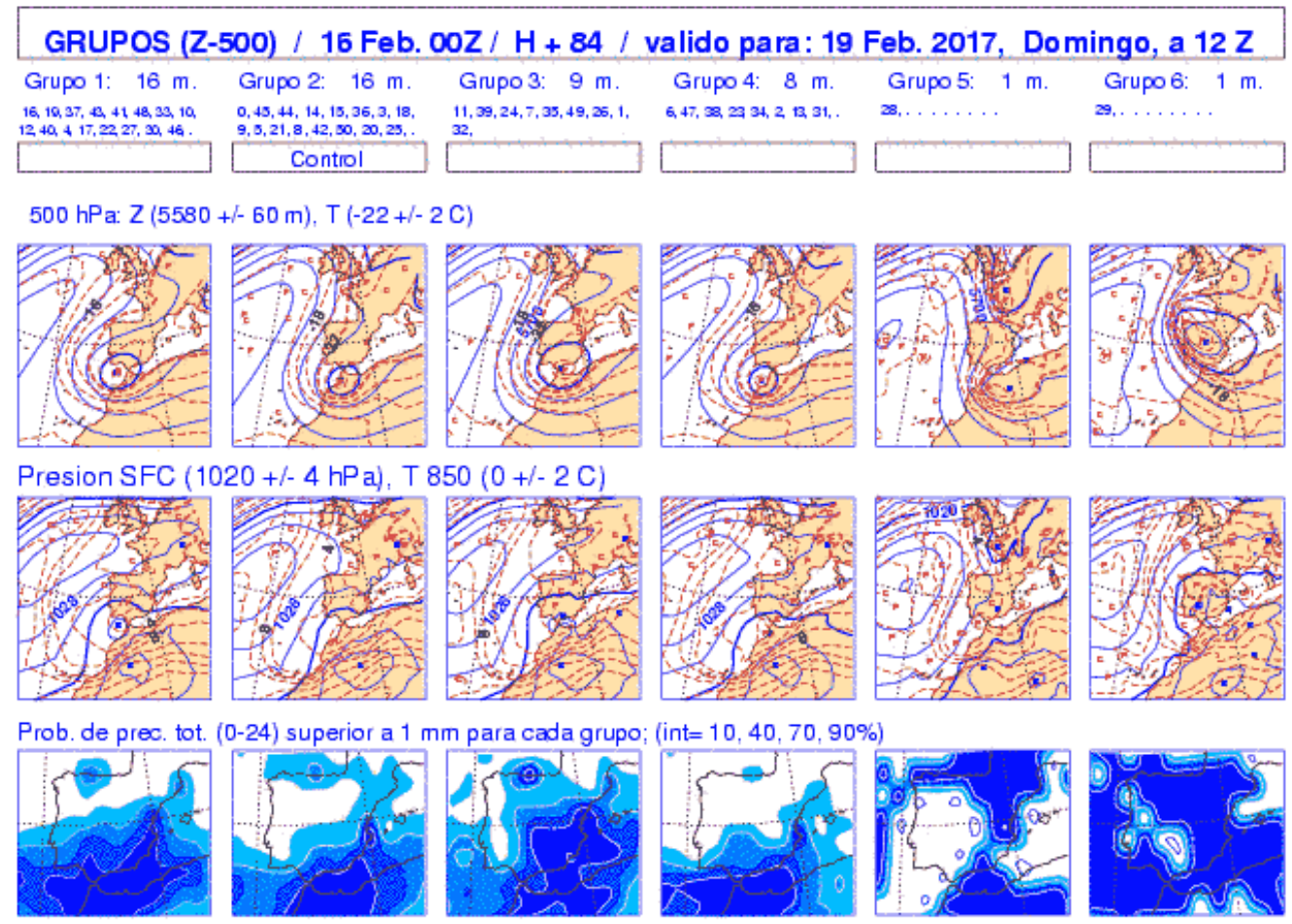

Figura 55.8: Grupos del ECENS. AEMET 2017.

\subsubsection{ECENS: escenarios}

Los grupos (ver sección 27.4.1 en la página 406) que ofrece esta pasada del ECENS se muestran en la Figura 55.8. Puede observarse que los grupos 1 y 3 , con 16 y 9 miembros respectivamente, configuran dos escenarios muy parecidos, por lo que pueden agruparse en un supergrupo (ver supergrupos, sección 27.8 en la página 409). De igual forma se pueden agrupar en un segundo supergrupo los grupos 2 y 4 , que configuran otros dos escenarios similares con 16 y 8 miembros respectivamente, quedando el miembro de control en el grupo 2. Quedan dos grupos más (el 5 y el 6) con configuraciones muy diferentes pero que solo constan de un miembro; su probabilidad es, en principio, irrelevante y podemos agruparlos en un tercer supergrupo.

En resumen, obtendríamos un conjunto de tres supergrupos (Figura 55.9). El A, con $49 \%$ de probabilidad, el B con un $47 \%$ de probabilidad e incluyendo el miembro de control y un tercer supergrupo, el C, con una probabilidad de $4 \%$ y muy discrepante respecto a los supergrupos A y B. La Figura 55.9 muestra los supergrupos generados por el meteorólogo predictor de AEMET (autor de este capítulo), basándose en los grupos correspondientes del ECENS que se muestran en la Figura 55.8.

SUPERGRUPOS // 16 Feb. 00Z / H + 84 / 19 Feb. 2017, Domingo, a 12 Z

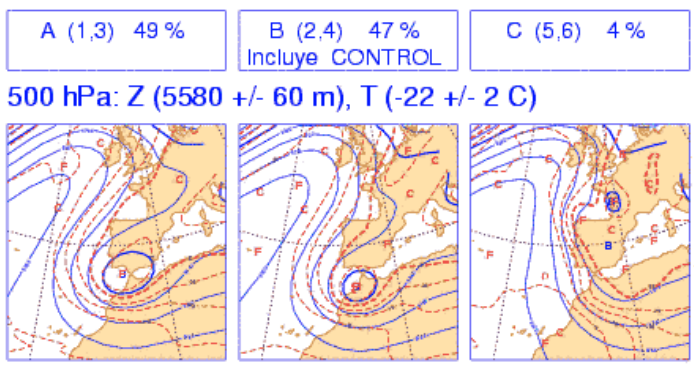

Presion en SFC $(1020+/-4 \mathrm{hPa})$, T en $850(0+/-2 \mathrm{C})$

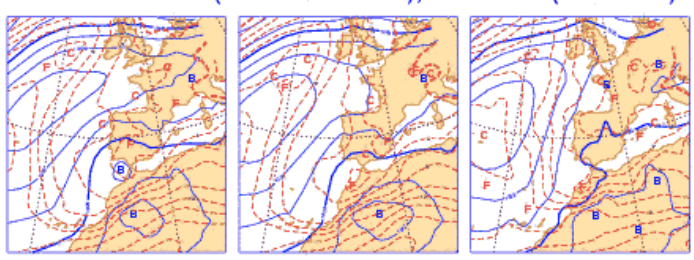

Prob. de Prec. (0-24) sup. a $1 \mathrm{~mm}$, para cada supergrupo:(int=10,40,70,90\%)
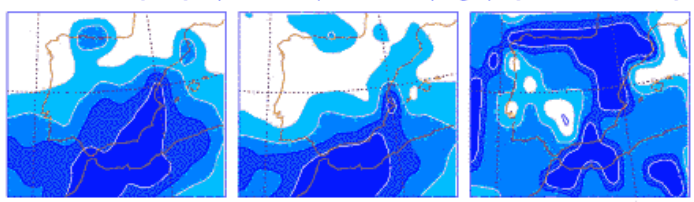

Figura 55.9: Supergrupos generados por el meteorólogo de AEMET (ver texto). AEMET 2017. 


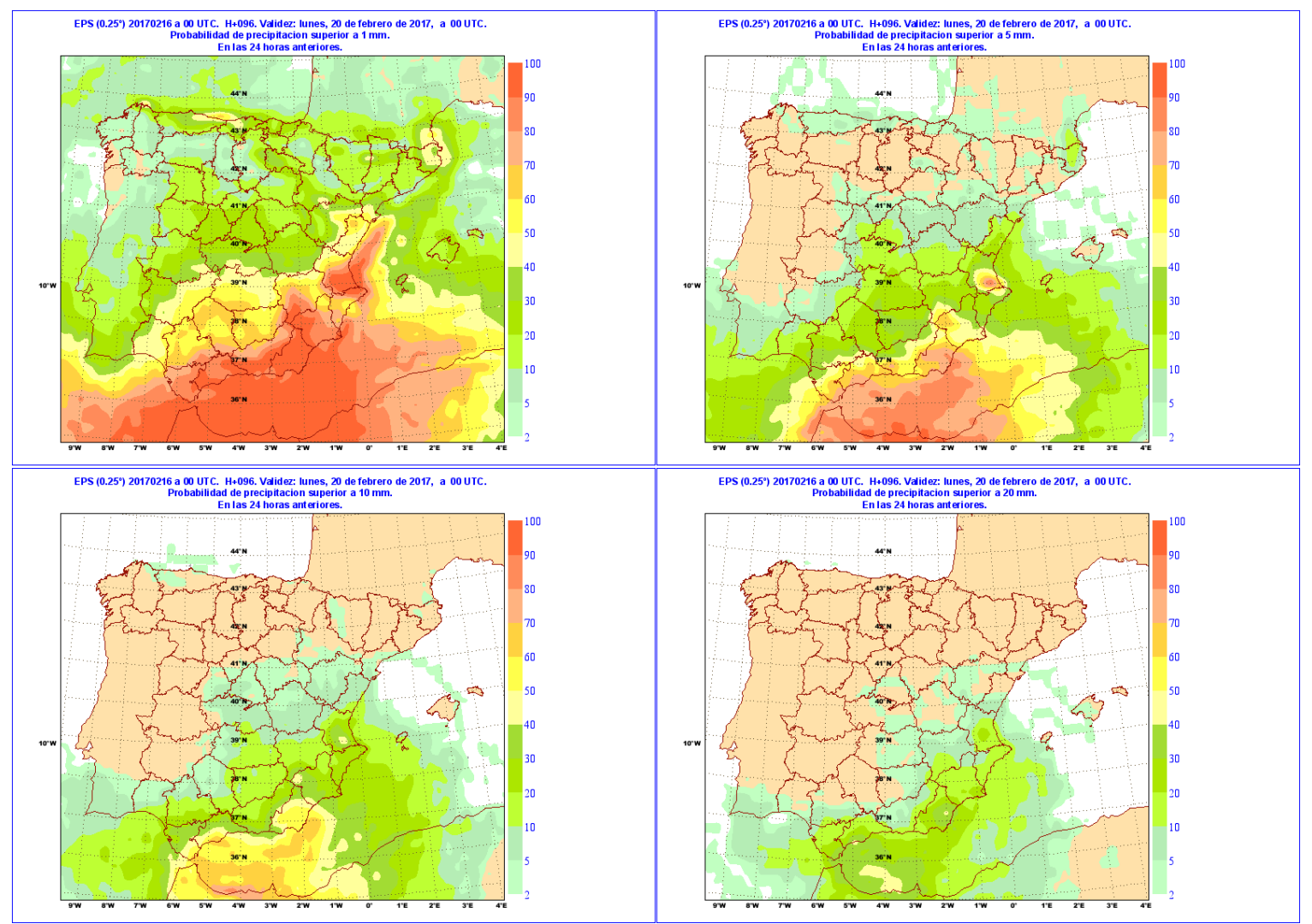

Figura 55.10: Probabilidades de precipitación del ECENS sobre la Península y Baleares por encima de umbrales, de arriba abajo y de izquierda a derecha, 1, 5, 10 y $20 \mathrm{~mm}$. AEMET 2017.

\subsubsection{Probabilidades}

Pasemos ahora a estudiar la probabilidad (ver mapas de probabilidad, sección 27.6.1 en la página 416) de precipitación acumulada en las 24 horas que se obtiene de la media de los 51 miembros de la pasada del ECENS. En la Figura 55.10 se presentan los mapas de probabilidad superior a $1,5,10$ y a $20 \mathrm{~mm}$. A la vista de estos datos se pueden prever precipitaciones que acumularán al menos $1 \mathrm{~mm}$ en las provincias de Cádiz, Málaga, Almería, Murcia, Valencia y las ciudades autónomas de Ceuta y Melilla, con una probabilidad superior al $80 \%$. Con una probabilidad menor (entre $40 \%$ y $70 \%$ ), estas precipitaciones se extenderían también el resto de las provincias andaluzas, suroeste de Badajoz, Ciudad Real, Albacete y resto de la Comunidad Valenciana. Aparecen también señales de precipitación en puntos del litoral cantábrico y en el nordeste de Cataluña, con una probabilidad entre $40 \%$ y $60 \%$. En el resto de la mitad sur peninsular y en Baleares, la probabilidad de precipitación está ya por debajo del $40 \%$.

En cuanto a precipitaciones que superan los $10 \mathrm{~mm}$, aparecen señales entre $50 \%$ y $70 \%$ en puntos del litoral de Cádiz, Málaga, Almería y en las ciudades de Ceuta y Melilla. Incluso pueden observarse dos pequeños puntos, en el litoral de Málaga y al norte del Parque Natural del cabo de Gata, donde existe una probabilidad entre $40 \%$ y $50 \%$ de que se acumulen más de $20 \mathrm{~mm}$. Las probabilidades para acumulaciones presentan valores muy bajos. Comparando el mapa de precipitación acumulada ofrecido por el modelo determinista, es consistente con la salida del ECENS. Esta consistencia ya se puso de manifiesto al comparar el campo operativo con el de control, pero la cantidad de precipitación está claramente subestimada en el caso del ECENS.

\subsubsection{Predicción}

En conclusión, con la información que nos ofrecen el ECHRES y el ECENS, pueden predecirse precipitaciones a tres días vista en Andalucía con probabilidad, aunque baja, de que sean intensas en los litorales del mar de Alborán, especialmente en Málaga, Almería, Cádiz, Ceuta y Melilla. 


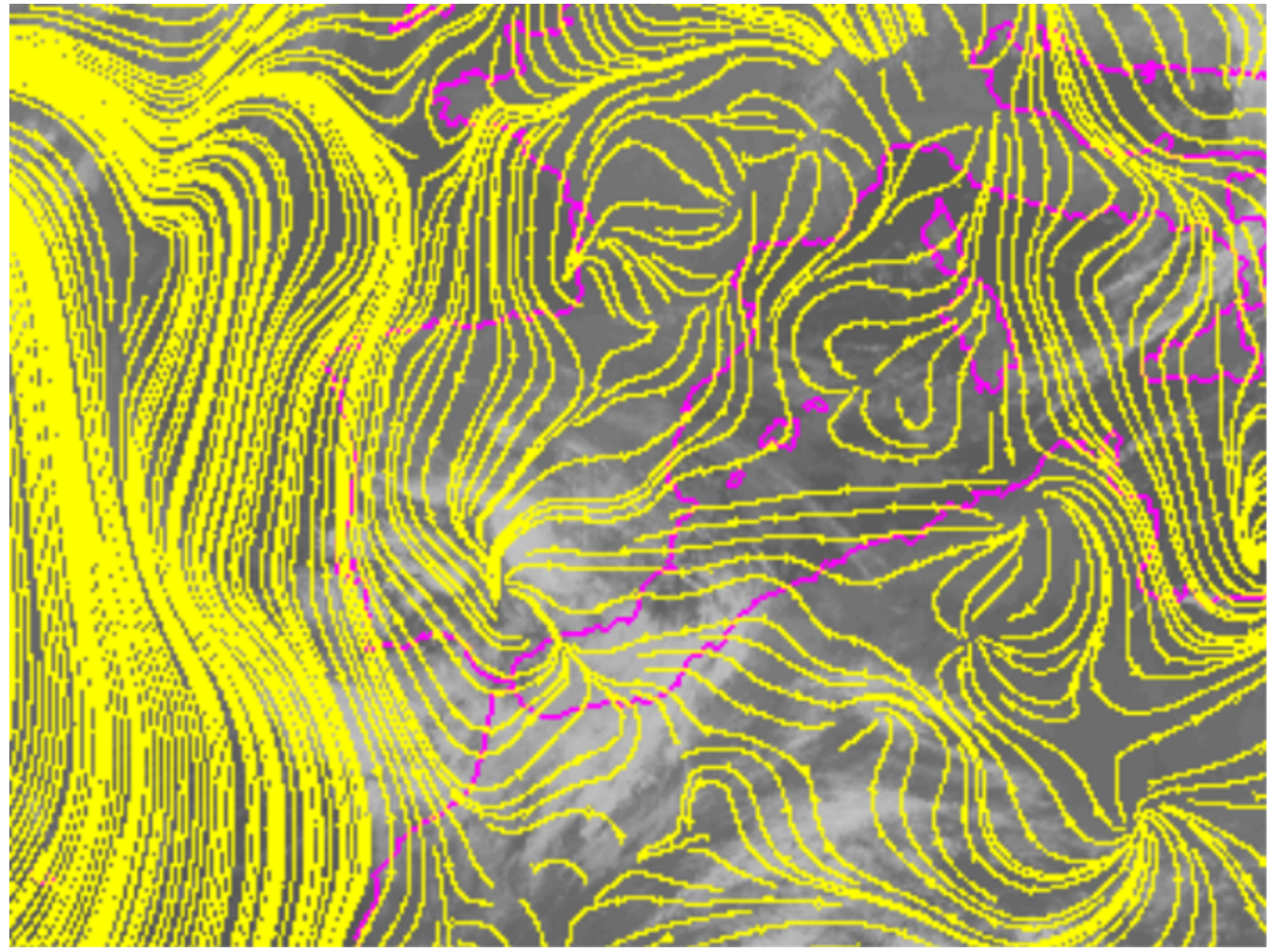

Figura 55.11: Mapa de líneas de corriente en niveles bajos previsto por la pasada de ECHRES de 12 horas antes del episodio, en el que se aprecia una clara línea de convergencia sobre la ensenada donde se sitúa el área urbana de Málaga, que junto con el paso de la DANA en altura, parece ser la responsable del fenómeno. AEMET 2017.

\subsection{Predicción de corto plazo}

En las siguientes pasadas tanto del ECENS como del ECHRES, se podía seguir manteniendo esta predicción. Podemos afirmar que en este caso la predicción de corto plazo es consistente con la de medio plazo, según se va acercando el evento. Usando campos predictivos más potentes, propios del corto plazo, se muestra en la Figura 55.11 el mapa de líneas de corriente en niveles bajos previsto por el ECHRES de 12 horas antes del episodio, en el que se aprecia una clara línea de convergencia sobre la ensenada donde se sitúa el área urbana de Málaga, que junto con el paso de la DANA en altura, parece ser la responsable del fenómeno.

\subsection{Comparación con observacio- nes}

Recopilada la información relativa a la observación del día 19 de febrero, llama la atención la tromba de agua que cayó en el área de Málaga capital, donde se acumularon más de $150 \mathrm{~mm}$ (la mayoría caídos de madrugada) y que en Almería, uno de los puntos donde había ligera probabilidad de precipitaciones superiores a $20 \mathrm{~mm}$ en 24 horas, no lloviera nada. Fuera de estas dos zonas, la predicción del ECENS resultó aceptable.

En la Figura 55.12 en la página siguiente se presentan el análisis a las 12 UTC en $500 \mathrm{hPa}$ y la correspondiente imagen de satélite. En el análisis de $500 \mathrm{hPa}$ se observa que el núcleo de la DANA se sitúa a las 12 UTC justo en la embocadura atlántica del Estrecho, la zona de máxima advección de vorticidad queda sobre el mar de Alborán. En el canal visible de la imagen de satélite ya puede verse la parte delantera de la DANA sobre el área del Estrecho, zona susceptible de gran actividad convectiva, lo cual confirmarán los datos de observación.

En la Figura 55.13 en la página 837 puede verse, por un lado, la acumulación de precipitación en 24 horas registrada por las estaciones automáticas y, por otro, el campo de precipitación acumulada en 24 horas observada, construido mediante interpolación de los datos registrados. 

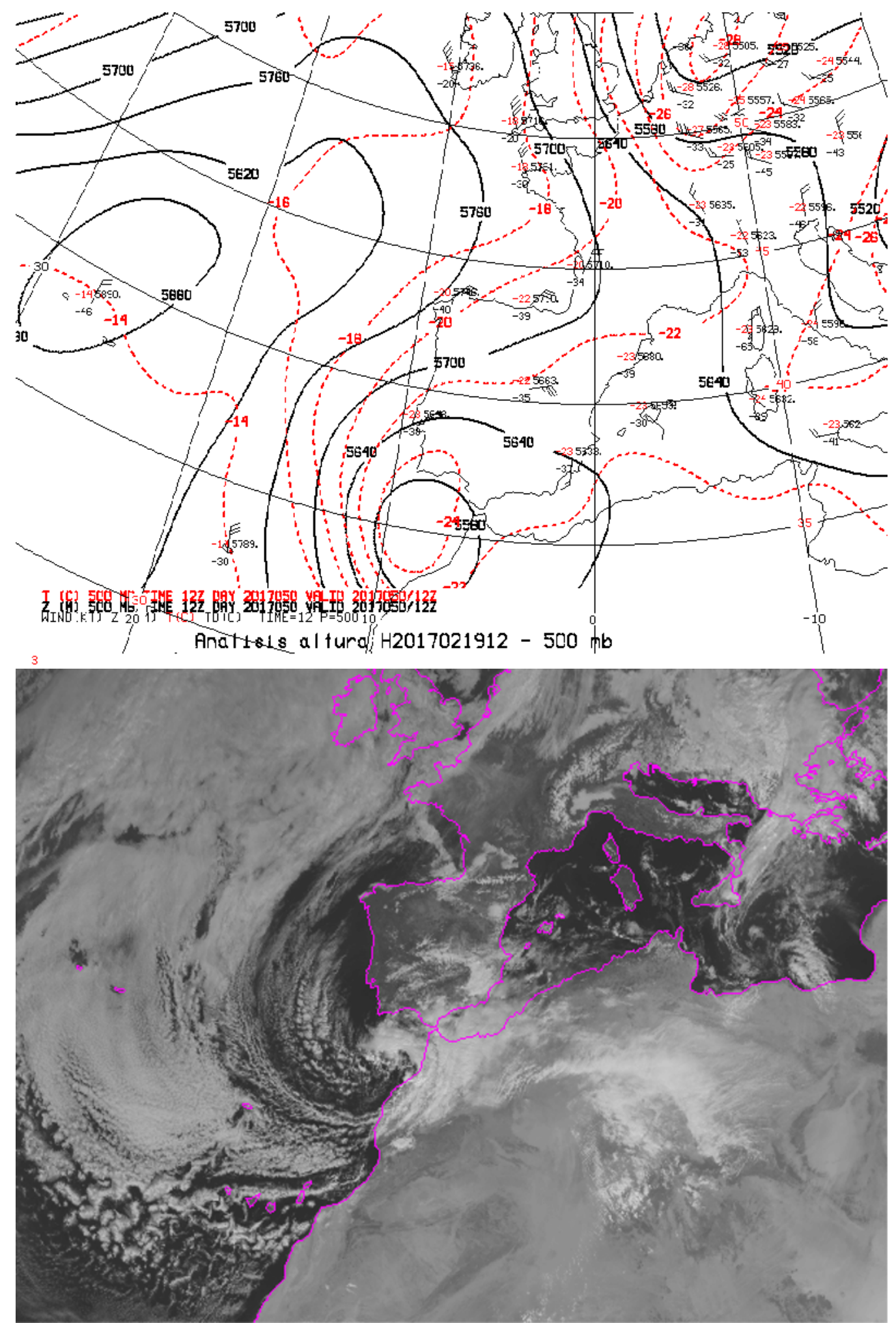

Figura 55.12: Análisis en 500 hPa a las 12 UTC del día 19 de febrero de 2017 y la correspondiente imagen de satélite en el canal visible. AEMET 2017. 

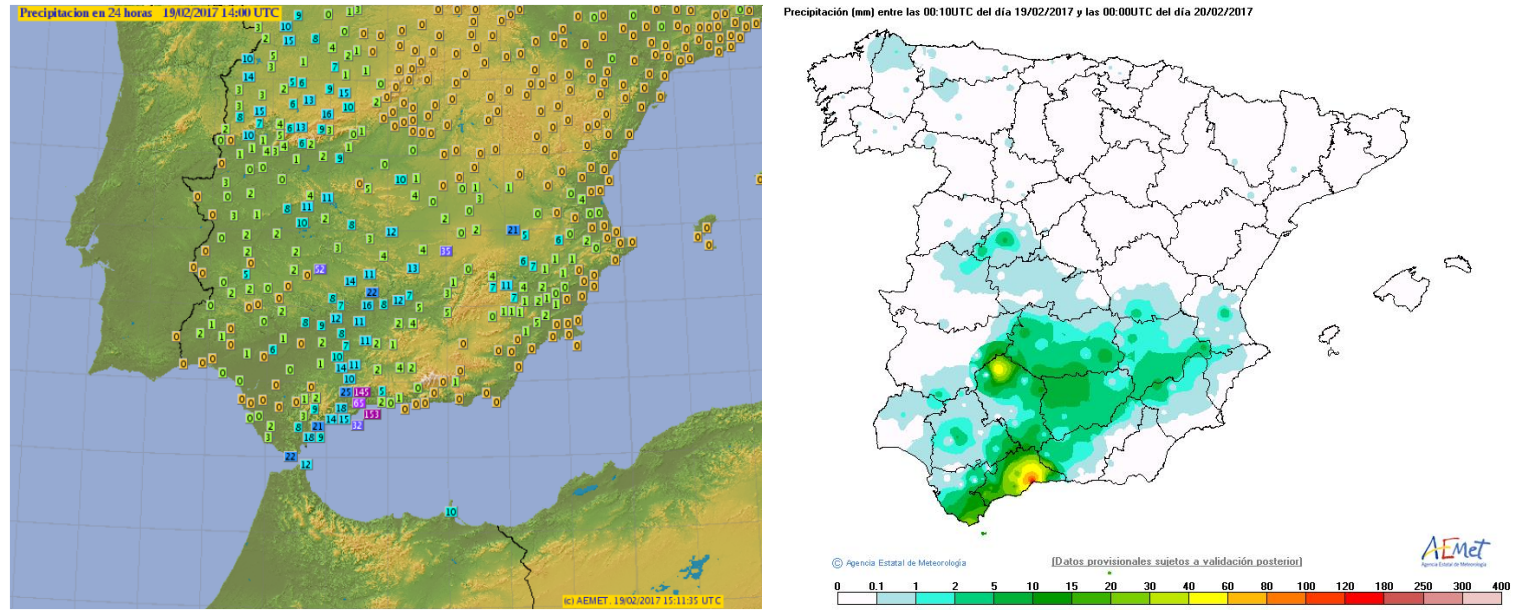

Figura 55.13: A la izquierda precipitaciones acumuladas en 24 h registradas en las estaciones el día 19 de febrero de 2017. A la derecha, correspondiente interpolación conformando un mapa espacial continuo de precipitación estimada a partir de las observaciones para el mismo día. AEMET 2017.

En la Figura 55.14 pueden verse las imágenes de radar, mostrando reflectividad en el área de interés. El fenómeno de Málaga fue puramente convectivo. En las primeras horas de la madrugada del 19 de febrero ya se podían observar señales radar de fuerte reflectividad sobre la ciudad. La actividad convectiva fue extendiéndose y organizándose durante las horas siguientes.

\subsection{Conclusiones}

Es evidente que el ECENS por sí solo no es suficiente para predecir este tipo de fenómenos extremos y de tan pequeña escala, ya que escapa a su resolución horizontal (unos $18 \mathrm{~km}$ en 2017). Para ello el predictor debe de actualizar su predicción con pasadas posteriores del ECENS, y contrastarla con la información que proporcionan los modelos deterministas de mayor resolución, por ejemplo el ECHRES, mostrado en este capítulo, o el HARMONIE-AROME (sec. 20.4 en la página 310). Es precisamente en estos casos extremos donde sería ideal una predicción lo más afinada y detallada posible para la sociedad. No obstante, el comportamiento del modelo y del sistema de predicción por conjuntos a escala sinóptica y a tres días vista fue, a nuestro juicio, aceptable para realizar una buena predicción.
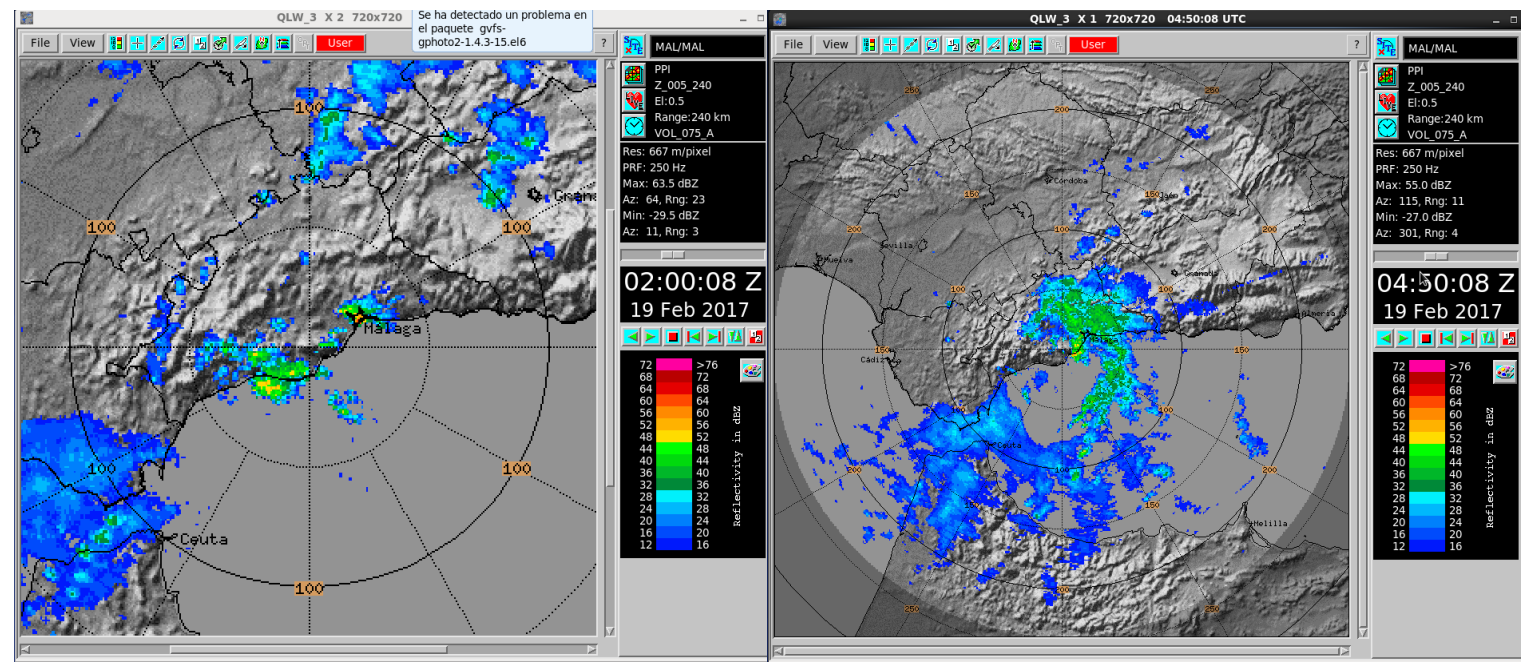

Figura 55.14: Imágenes de reflectividad del radar de Málaga correspondientes al desarrollo del episodio. AEMET 2017. 


\subsection{Referencias}

[1] LiLlo, Ignacio. La lluvia deja más de 153 litros en el Centro y la zona Este. 2017. URL: http : / /www . diariosur . es / malaga/ 201702/19/tromba-lluvia-granizo- deja - 20170219070440 . html (visitado 01-02-2018) (citado en página 830).

[2] Persson, Anders. "User guide to ECMWF forecast products". En: Ecmwf March (2011), página 127 (citado en página 828). 
